\title{
New Clues that May Link Osteoporosis to the Circ ulating Lipid Profile
}

\author{
Catalina Poiana ${ }^{1,2}$, Valentin Radoi ${ }^{2 *}$, Mara Carsote1,2, John P. Bilezikian $^{3}$ \\ 1"C. I. Parhon” National Institute of Endocrinology, Bucharest, Bucharest, Romania; ${ }^{2}$ University of Medicine and Pharmacy \\ “Carol Davila”, Bucharest, Bucharest, Romania; ${ }^{3}$ College of Physicians and Surgeons, Columbia University, New York, NY \\ USA
}

Bone Mineral Density (BMD) is a gold standard for the diagnosis of osteoporosis and is also important in the assessment of fracture risk. Other risk factors have been identified that together make up fracture risk assessment tools such as FRAX. Another potential factor, circulating lipids, has been suggested because of reports linking statins to fracture risk reduction. We analyzed the lipid profile in a cohort of women diagnosed with postmenopausal osteoporosis based on bone density determination: 610 women with osteoporosis (mean lumbar spine T-score $-3.16 \pm 0.81$, mean yrs. since menopause 15.79 \pm 8.9 ) were grouped according to age at evaluation (< 50 years, 51-60 years, 61-70 years, > 70 years), the presence/absence of a history of a fragility fracture, statin and/or antiresorptive drug use. There was no correlation between BMD and Body Mass Index (BMI: $\left.P>0.05, r^{2}<0.02\right)$. However, when BMD was correlated with both BMI and the lipid profile (Triglycerides, Cholesterol, LDLc, HDLc), significant correlations were found in 5 cohorts: 51-60 years with fractures $\left(n=61, r^{2}=0.14, P<0.01\right), 61-70$ years $\left(n=201, r^{2}=0.09, P<0.01\right)$ with fractures $\left(n=88, r^{2}=0.14, P<0.01\right)$ or without fractures $\left(n=113, r^{2}=0.24, P=0.02\right)$ and over 70 years $\left(n=247, r^{2}=0.11, P<0.01\right)$.

Keywords: osteoporosis; bone mineral density; lipid; cholesterol; triglycerides; HDL-cholesterol

Bone Research (2013) 3: 260-266. doi: 10.4248/BR201303004

\section{Introduction}

Osteoporosis is a major health problem because of the associated low-trauma fractures, morbidity and mortality associated with it, and the cost of treatment. While statins are not used, nor even considered as a potential therapeutic class for osteoporosis, some studies, dating back to 1999, have shown a potential beneficial effect of statins on bone metabolism (1). Plausible molecular mechanisms include the inhibition of the mevalonate pathway, the same pathway that is inhibited by bisphosphonates (2), activation of the bone morphogenetic protein-2 promoter (BMP-2), which acts as an osteoblast growth factor (3-4) and reduction of oxidative stress

*Correspondence: Valentin Radoi

E-mail: ilumma.conquer@yahoo.co.uk

Tel: +4 0743183445; Fax: +4 0318148462

Received 05 May 2013; Accepted 04 J uly 2013 through up-regulation of NAPDH oxidase 4 (Nox4) (5). Although some studies have shown that statins reduce fracture risk, the issue is farfrom being settled (6-13). The largest meta-analysis, which included 151500 subjects of whom 9946 were statin users, suggested that statin use was associated with reduced fracture risk, but other analyses have not been confimatory (8).

Hypotheses linking lipids to skeletal health include several potential mechanisms. Age-related increases in interleukin-6 (IL-6) and C-reactive protein (CRP) (14) have been associated with osteoporosis (15), especially in overweight adults (16). Oxidized lipids, characteristic of hyperlipidemia, modulate the resorptive effects of parathyroid homone (PTH) (17), inducing the expression of RANKL (18) and suppressing the differentiation of bone marrow stromal cells to osteoblasts (19). In this study, we sought to gain additional information beyond what has been reported so far (20-22) on bone mineral density among postmenopausal women with osteo- 
porosis based upon their history of statin use and fragility fractures. We conducted this test of the hypothesis because new preclinical evidence has been published recently, while clinical studies, especially on a population such as ours, are lacking.

\section{Materials and methods}

The study included 610 consecutive patients who were treated for osteoporosis at the "C. I. Parhon", National Institute for Endocrinology, Romania in the National Program for Osteoporosis which offered free medication. The inclusion criteria was a diagnosis of osteoporosis as defined by densitometric parameters with no exclusion criteria regarding these parameters orlipids.

The data on age and age at menopause, in years, were obtained from the patients' records or from the patient directly. The presence or absence of a fracture was determined for each patient by spine radiography as recorded in the patient's file only by the primary radiologist who knew the purpose of the evaluation which was to determine whether or note vertebral fractures were present. Lumbar spine BMD $\left(\mathrm{g} \cdot \mathrm{cm}^{-2}\right)$ was measured by dual energy X-ray absorptiometry (DXAGE-Lunar; L1-L4 site). Total cholesterol, HDL-cholesterol and triglycerideswere measured by spectrophotometric enzymatic colorimetric tests using a COBAS INTEGRA 400 plus (Roche) and $D L-c h o l e s t e r o l$ by using the formula DLC =Total cholesterol-(Triglycerides/5 + HDLc). Nomal ranges were considered to be: $120-200 \mathrm{mg} \cdot \mathrm{dL}^{-1}$ for total cholesterol, 35-150 mg $\cdot \mathrm{dL}^{-1}$ for triglyc erides, $40-65 \mathrm{mg} \cdot \mathrm{dL}^{-1}$ for HDLc, $60-160 \mathrm{mg} \cdot \mathrm{dL}^{-1}$ for $D L C$. Body mass index (BMI) was calculated by the formula $\mathrm{BMI}=$ weight.height ${ }^{-2}$, where height is expressed in meters and weight in kilograms. We considered patients with a T-score between -1.0 and -2.49 to be osteopenic and those with a T-score $<-2.5$ to have osteoporosis (23). This study included patients seen between J a nuary 2000 and March 2011.

The statistical analysis was camied out using Epilnfo 7 provided by the Center for Disease Control and Pre- vention (CDC, USA). Using this program we measured means, standard deviations, multivariate linear regressions and single linear regressions expressed as $r^{2}$ or $r$ and type 2, two tailed, P-values expressed as P. For the multivariate regressions, BMD was the dependent variable while BMI, DLC, HDLc, TG and total Cholesterol were independent variables. A $P$ value of $\varangle 0.05$ was considered to be statistic ally signific ant. The $\beta$ value was 0.20 (a $B: a$ ratio of $4: 1$ ). All study partic ipants gave written or oral consent.

\section{Results}

All subjects were postmenopausal women (mean years since menopause: $15.8 \pm 8.9$ years) with osteoporosis (mean Tscore: $-3.16 \pm 0.81$ ) and were grouped according to age at diagnosis ( $<50$ years, $51-60$ years, $61-70$ years and $>70$ years) and the presence or absence of a history of fragility fracture (Table 1). All patients received vitamin D and calcium supplements. 402 patients received bisphosphonates, 151 selective estrogenreceptor modulators (SERMs) and 46 received vitamin D and calcium alone. 150 patients also received statins, 145 patients received both bisphosphonates and statins. Statin usage could not be established in 94 patients. There were no statistically significant differences found between vitamin $D$ levels and calcium levels for these patients $(P>0.05$ for both variables in the entire cohort and all the subgroups).

The included parameters as well as the onesthat were not included in the comelation were based on the fact that we designed this study to reflect, as much as possible, a real world scenario. The analysiswas based on the known comelation between osteoporosis and age, and between lipid levels with age. We chose to select subgroups by decades of age because this allowed us to more easily show a clinically signific ant correlation than by using logistic regression which would not have pinpointed specific subgroupsas clearly.

Table 1 Baseline patient characteristics

\begin{tabular}{|c|c|c|c|c|c|c|c|c|c|c|}
\hline \multirow[b]{2}{*}{ Age at diagnosis } & \multicolumn{10}{|c|}{ Mean \pm SD } \\
\hline & $\begin{array}{l}\text { Age } \\
\text { /years }\end{array}$ & $\begin{array}{l}\text { post-menop } \\
\text { ause/years }\end{array}$ & $\begin{array}{l}\text { BMI/ } \\
\text { height } \cdot \mathrm{kg}^{-2}\end{array}$ & $\begin{array}{l}\mathrm{BMD} / \\
\mathrm{g} \cdot \mathrm{cm}^{-2}\end{array}$ & $\begin{array}{l}\text { Tscore/ } \\
\text { SD }\end{array}$ & $\begin{array}{l}\text { Zscore/ } \\
\text { SD }\end{array}$ & $\begin{array}{l}\text { Cholesterol/ } \\
\mathrm{mg} \cdot \mathrm{dL}^{-1}\end{array}$ & $\begin{array}{l}\mathrm{HDLC} / \\
\mathrm{mg} \cdot \mathrm{dL}^{-1}\end{array}$ & $\begin{array}{l}\text { DLC/ } \\
\mathrm{mg} \cdot \mathrm{dL}^{-1}\end{array}$ & $\begin{array}{l}\text { Triglyce rides } \\
/ \mathrm{mg} \cdot \mathrm{dL}^{-1}\end{array}$ \\
\hline All patients & $60.9 \pm 9.7$ & $15.7 \pm 8.8$ & $24.8 \pm 4.1$ & $0.7 \pm 0.1$ & $-3.1 \pm 0.8$ & $-1.8 \pm 0.9$ & $230.4 \pm 46.4$ & $60.6 \pm 15.9$ & $148.3 \pm 42$ & $111.5 \pm 60.5$ \\
\hline Under 51 years & $45.5 \pm 4.7$ & $8.1 \pm 6.9$ & $25.3 \pm 4.0$ & $0.8 \pm 0.1$ & $-3.0 \pm 0.8$ & $-2.6 \pm 0.9$ & $234.0 \pm 57.7$ & $57.5 \pm 13.5$ & $145.0 \pm 38.1$ & $104.0 \pm 78.7$ \\
\hline $51-60$ years & $55.3 \pm 2.9$ & $10.2 \pm 6.2$ & $25.0 \pm 4.1$ & $0.7 \pm 0.1$ & $-3.1 \pm 0.7$ & $-2.1 \pm 0.8$ & $226.8 \pm 40.9$ & $58.8 \pm 16.8$ & $148.5 \pm 37.7$ & $117.8 \pm 61.3$ \\
\hline $61-70$ years & $65.1 \pm 2.7$ & $17.8 \pm 5.4$ & $24.7 \pm 4.1$ & $0.7 \pm 0.1$ & $-3.1 \pm 0.6$ & $-1.5 \pm 0.6$ & $231.0 \pm 47.2$ & $62.1+16.4$ & $149.5 \pm 47.5$ & $112.8 \pm 58.6$ \\
\hline Over 70 years & $74.0 \pm 3.0$ & $26.6 \pm 6.4$ & $24.6 \pm 4.2$ & $0.7 \pm 0.1$ & $-3.2+1.0$ & $-1.3 \pm 0.8$ & $234.0 \pm 47.4$ & $63.9 \pm 14.0$ & $147.4 \pm 45.7$ & $101.7 \pm 46.6$ \\
\hline
\end{tabular}

BMI-Body Mass Index; BMD-Bone Mineral Density. 


\section{BMD and the Lipid Profile}

The multivariate regression for the entire study population showed no correlation between BMD (dependent variable) and $\mathrm{BMI}$, cholesterol, $D L C, \mathrm{HDLC}$ and triglycerides (independent variables) $\left(n=613, r^{2}=0.02, P>0.05\right)$. Even aftergrouping the patients according to fractures, no correlation was seen in the subjects with $(n=380$, $\left.r^{2}=0.03, P>0.05\right)$ or without previous fracture $(n=232$, $\left.r^{2}=0.06, P>0.05\right)$.

We next examined subgroups according to age. In subjects whose diagnosis of osteoporosis was ma de between ages 51 and 60, a signific ant multiva riate correlation was seen between BMD and the indices: $D L C$, HDLC, TG and Cholesterol $\left(n=61, r^{2}=0.14, P=0.003\right)$. For the same relationship between BMD and the composite lipid indices, a significant correlation was also obtained when the age of diagnosis was between 61 and 70 ( $n=201, r^{2}=0.09, P \varangle 0.01$ ). In this latter subgroup of patients, a signific ant correlation between BMD and $D L C, H D L C$, TG and Cholesterol was seen whether the subjects had sustained a fracture $\left(n=88, r^{2}=0.14, P \varangle 0.01\right)$ or had not $\left(n=113, \quad r^{2}=0.24, P=0.02\right)$. In the oldest group we studied, $>70$, we noted, when companing the same indices, a significant correlation ( $n=247, r^{2}=0.11, P \varangle 0.01$ ) although the significance of the correlation was no longer present if this older group was studied according to whether or not a fracture event occurred (Table 2).

Correlations between BMD and BMI, in the entire cohort or in the subgroups based on previous fracture (present/absent), on age (under 50 years, 51-60 years, 61-70 years, over 70 years) or on age and previous fractures (8 subgroups) were not statistically significant $(P>0.05)$.

\section{Correlations based on prescribed drugs}

There was no correlation in the cohort who were receiving statins $(n=150)$ between BMD and $D L C, H D L c$, TG and cholesterol ( $\left.P \varangle 0.001, r^{2}=0.06\right)$, as well as in the subgroup of patients with no previous fractures $(P \varangle 0.001$, $\left.r^{2}=0.06\right)$. A weak correlation was found for patients with previous fractures $\left(P \varangle 0.001, r^{2}=0.19\right)$.

In agreement with the data for all patients, data for patients taking statins showed a weak correlation for patients with a ges at diagnosis between 51 and 60 years. $\left(P \varangle 0.001, r^{2}=0.11\right)$ and more powerful correlations for patients between 61 and 70 years at diagnosis $(P \varangle 0.001$, $r^{2}=0.33$ ) and patients older than 70 years at diagnosis $\left(P \varangle 0.001, r^{2}=0.76\right)$. The correlations based both on these age groups and previous fracture state remained signific ant (Table 3).

For patients not taking statins $(n=364)$ the correlation between BMD and the lipid profile gave a minimal $r$ value, although a significant $P$ value was reached $(P<$ $\left.0.001, r^{2}=0.03\right)$. Similar results were obtained when these patients were grouped according to previous fracture state $\left(P \varangle 0.001, r^{2} \varangle 0.05\right)$. The subgroups of patients under 51 years at diagnosis or between 51 and 60 years at diagnosis showed no correlation, either as a whole or when grouped according to previous fracture state.

Patients not receiving statins who were diagnosed with osteoporosis at ages between 61 and 70 years showed a weak correlation $\left(P \varangle 0.001, r^{2}=0.11\right)$, which

Table 2 The results of the multivariate linear regression between BMD and LDLc, HDLc, TG and Cholesterol

\begin{tabular}{lccc}
\hline Age at diagnosis & Number of patients in cohort & Significance/P & Correlation $/ \mathrm{r}^{2}$ \\
\hline Entire cohort & 610 & $>0.05$ & 0.02 \\
With no previous fractures & 380 & $>0.05$ & 0.03 \\
With previous fractures & 232 & $>0.05$ & 0.06 \\
Slyears & 72 & $>0.05$ & 0.27 \\
With no previous fractures & 56 & $>0.05$ & 0.38 \\
With previous fractures & 16 & Cohort too small & Cohort too small \\
5lyears<age<60 years & 219 & 0.003 & 0.14 \\
With no previous fractures & 157 & $<0.001$ & 0.01 \\
With previous fractures & 61 & 0.003 & 0.14 \\
61years<ge<70 years & 201 & $\varangle 0.001$ & 0.09 \\
With no previous fractures & 113 & 0.02 & 0.24 \\
With previous fractures & 88 & $\varangle 0.001$ & 0.14 \\
$>70$ years & 118 & $\varangle 0.001$ & 0.11 \\
With no previous fractures & 51 & $>0.05$ & 0.35 \\
With previous fractures & 67 & $>0.05$ & 0.35 \\
\hline
\end{tabular}

BMD-Bone Mineral Density, LDLc-LDL-cholesterol, HDLc -HDL-cholesterol, TG-triglycerides. 
Table 3 The results of the multivariate linear regression between BMD and LDLc, HDLc, TG and Cholesterol for patients taking statins*.

\begin{tabular}{lccc}
\hline Age at diagnosis & Number of patients in cohort & Significance/P & Correlation $/ \mathrm{r}^{2}$ \\
\hline Entire cohort & 150 & $\varangle 0.001$ & 0.06 \\
With no previous fractures & 79 & $\varangle 0.001$ & 0.06 \\
With previous fractures & 71 & $\varangle 0.001$ & 0.19 \\
51 years <age $<60$ years & 48 & $\varangle 0.001$ & 0.11 \\
With no previous fractures & 34 & 0.025 & 0.24 \\
With previous fractures & 14 & $\varangle 0.001$ & 0.85 \\
61 years <age<70 years & 50 & $\varangle 0.001$ & 0.33 \\
With no previous fractures & 20 & $\varangle .001$ & 0.51 \\
With previous fractures & 30 & 0.037 & 0.27 \\
$>70$ years & 31 & $\varangle 0.001$ & 0.76 \\
\hline
\end{tabular}

BMD-Bone Mineral Density, LDLc-LDL-cholesterol, HDLc-HDL-cholesterol, TG-triglycerides. *The results for patients under 51 years (entire group, with or without previous fractures) and the results for patients over 70 years with or without previous fractures were not statistically significant $(P>0.05)$.

improved after grouping according to previous fracture state, especially for the women with no previous fractures $\left(P \varangle 0.001, r^{2}=0.29\right.$ and $\left.P=0.029, r^{2}=0.52\right)$. A more powerful correlation was obtained for patients diagnosed after the age of 70 years $\left(P<0.001, r^{2}=0.28\right.$ ), correlation which remained significant for patients with no previous fractures $\left(\mathrm{P}=0.005, \mathrm{r}^{2}=0.52\right)$

When taking into account only those receiving antiresorptive drugs (bisphosphonates or SERMS), the entire cohort presented a modest correlation between BMD and the circulating lipid profile $\left(P=0.04, r^{2}=0.30\right)$. After taking into account previous fracture history, correlations lost their signific ance. Yet a ga in, by a ge subgroups, significant correlations were present for the women diagnosed with osteoporosis between the ages of 51 and 60 years $\left(P=0.05, r^{2}=0.23\right)$ and those diagnosed after the age of 70 years $\left(P=0.02, r^{2}=0.55\right)$. The correlations maintained their significance when taking into account previous fractures for each group $\left(P=0.05, r^{2}=0.29\right.$ and $\left.\mathrm{P}=0.003, \mathrm{r}^{2}=0.55\right)$.

Taking into account patients who used antiresorptive drugs and grouping them according to previous fracture state and statin use, we discovered strong correlations for those who had no previous fractures and did not take statins ( $\left.P \varangle 0.001, r^{2}=0.72\right)$ and for those who had previous fractures and were prescribed statins $(P<0.001$, $\left.r^{2}=0.87\right)$.

\section{BMD and lipid fractions}

A positive correlation between BMD and HDL-cholesterol in the entire cohort was significant $(r=0.05, P \varangle 0.0001$; figure 1). In the subgroup of patients who were under 51 years of age at diagnosis, there was an unexpected inverse correlation $(r=0.190, P \varangle 0.001)$.

Univariate linear regressions when other age subgroups were analyzed showed positive correlations for patients at an age at diagnosis between 51 and 60 years ( $r=$ $0.073, P \varangle 0.0001), 61$ and 70 years $(r=0.164, P \varangle 0.0001)$ and for those over 70 years $(r=0.103, P \varangle 0.0001)$. Correlations for all the subjects who were diagnosed after reaching the age of 51 years were positive and significant ( $r=0.104, \mathrm{P} \varangle 0.000$ 1; figure 2) (Table 4).

When analyzing the correlations between BMD and DLC in the entire cohort or its subgroups according to previous fractures, as well as according to age and/or previous fractures (15 correlations), we obtained only

Table 4 The results of the univariate linear regression between BMD and HDLc.

\begin{tabular}{lccc}
\hline Age at diagnosis & Number of patients in cohort & Significance/P & Correlation/ $\mathrm{r}$ \\
\hline Entire cohort & 610 & $\varangle 0.001$ & 0.050 \\
$<51$ years & 72 & $\varangle 0.001$ & -0.190 \\
51 years $<$ age $<60$ years & 219 & $\varangle 0.001$ & 0.073 \\
61 years $<$ age $<70$ years & 201 & $\varangle 0.001$ & 0.164 \\
$>70$ years & 118 & $\varangle 0.001$ & 0.103 \\
$>51$ years & 538 & $\varangle 0.001$ & 0.104 \\
\hline
\end{tabular}

BMD - Bone Mineral Density, HDLc - HDL-cholesterol. 


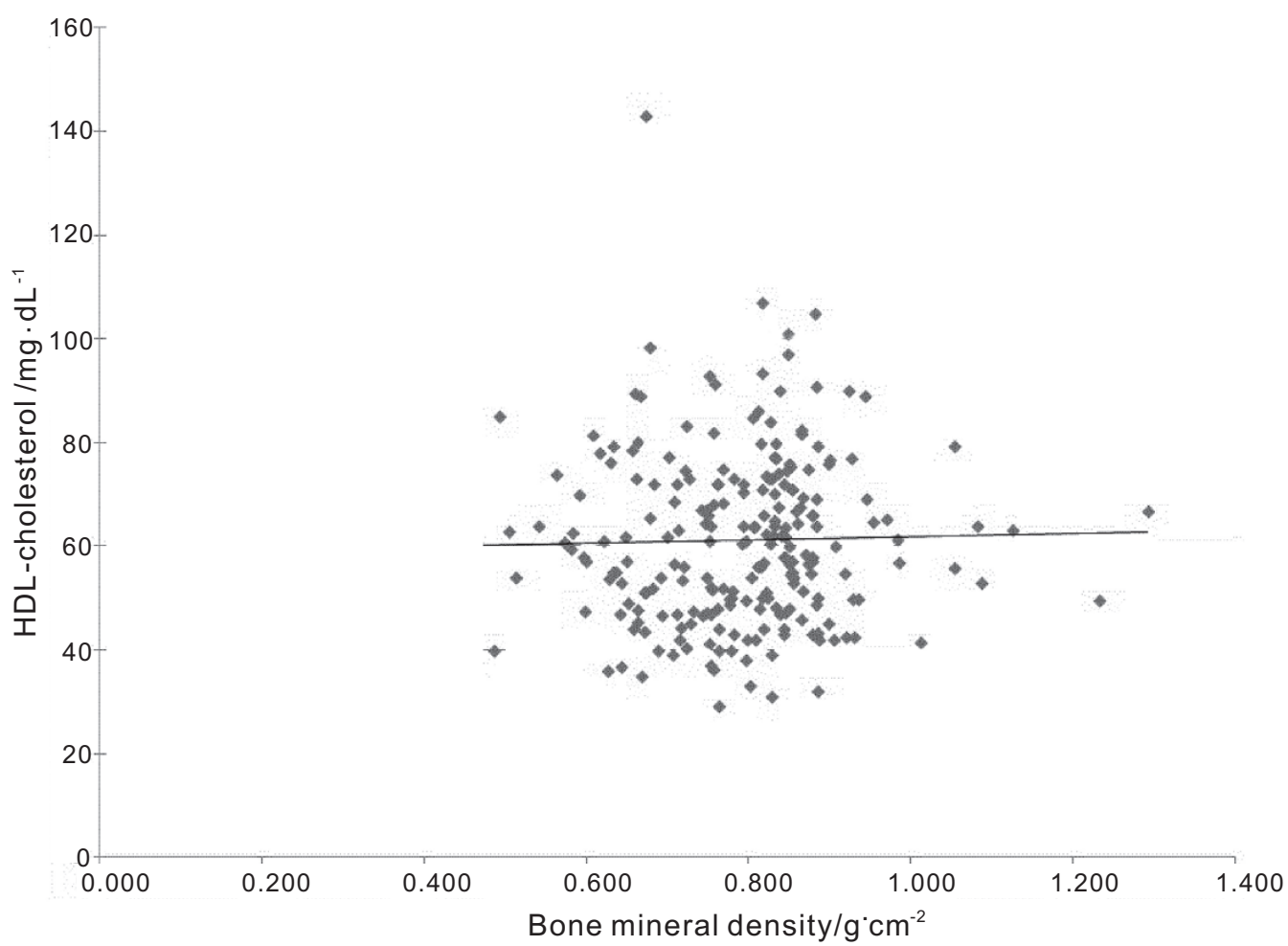

Figure 1 The trendline for all the patients, according to the linear regression between HDLc and Bone Mineral Density $(r=0.05)$. This graph shows the presence of a modest correlation, which is what we expected out of our study, as HDLc should be just another piece of the lipid puzzle in osteoporosis.

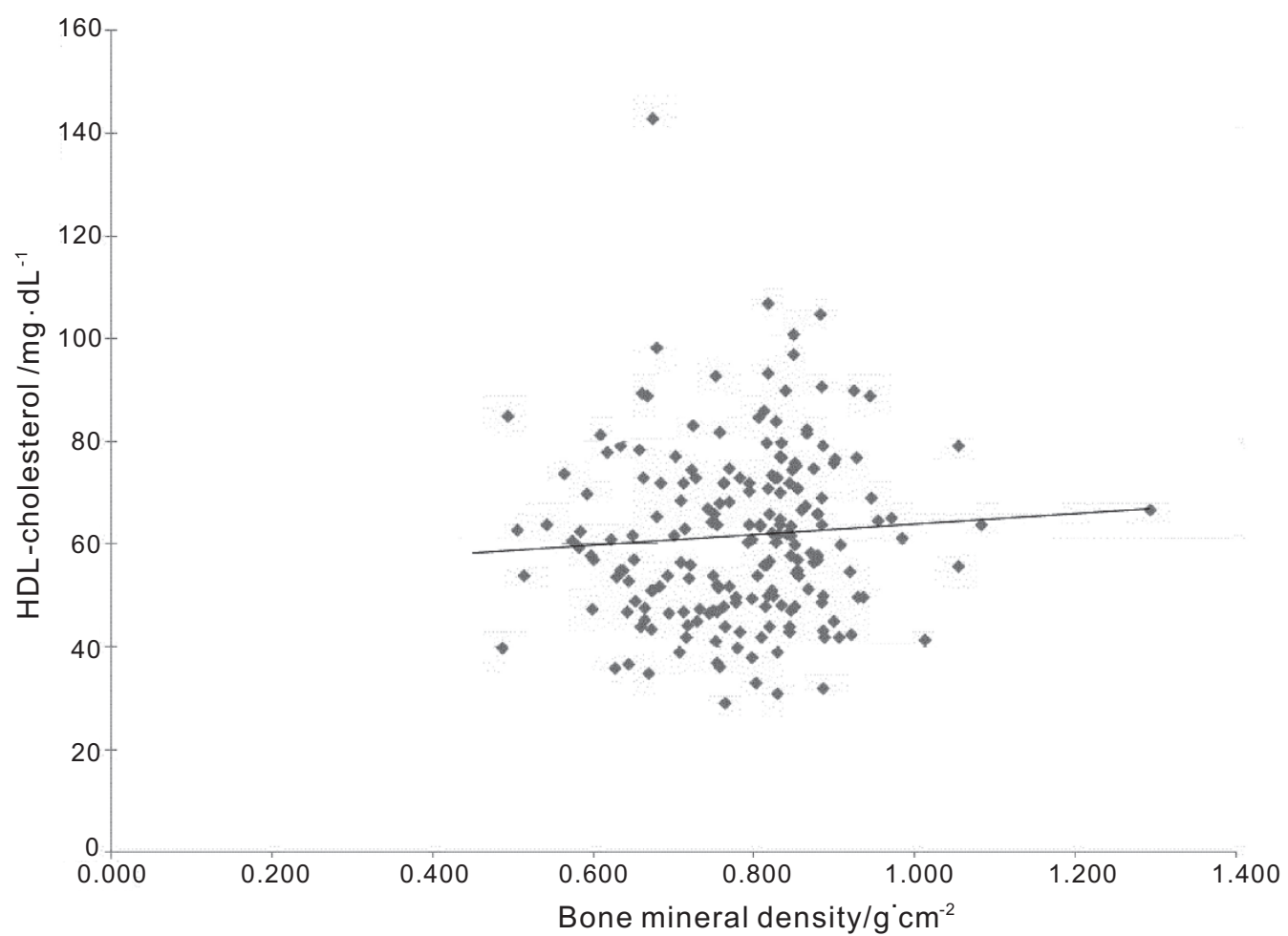

Figure 2 The trendline for all the patients, according to the linear regression between HDLc and Bone Mineral Density $(r=-0.104)$. This graph further substantiates the possibility of a link between Bone Mineral Density and the circulating lipid profile in women diagnosed after 50 years. 
results that were not significant $(\mathrm{P}>0.05)$ and that presented no correlation $\left(r^{2}<0.04 ;\right)$. Similar results were obtained for correlations between BMD and TG $(P>0.05)$ and BMD and total Cholesterol $(P>0.05)$.

\section{Disc ussion}

The results presented in this report provide support for an association between osteoporosis and the circulating lipid profile. Significant correlations between BMD and the lipid profile were demonstrated among certain demographically defined populations with an emphasis on patients older than 51 years.

Our results are supported by previous findings published in the last decade. Makovey et al have shown that BMD is significantly negatively correlated with total cholesterol and $D L C$ in postmenopausal women not receiving homone replacing therapy (HRT) and with HDLC in postmenopausal women receiving HRT (24). Orozco et al have shown 'that hyperlipidemia could be associated with osteoporosis" (22), while Tankó et al, in a longitudinal study, which included postmenopausal women between 50-75 years, showed that an increase in senum cholesterol was associated with a decrease in spine BMD, irrespective of BMI (25). Uyama et al demonstrated a "significant correlation of plaque score with total cholesterol level and low total BMD" (26). Not all studies have shown these correlations. For example, in the pros pective study of Samelson et al (27) and the two crosssectional studies of Solomon et al (28) and Wu et al (29), such correlations could not be demonstrated.

Studies including only Caucasian subjects have primarily shown, as we have, a positive correlation between HDLc and BMD (30). Apart from ethnicity, a second possible confounder is represented by the existence of numerous genes shown to influence both HDLc and BMD through a pleiotropic effect (eg ABCG8, APOE, ESR1) (31). The results, in the subgroup analysis, if replicated in a larger study, would also suggest that statins protect patients with no history of previous fractures $\left(P \measuredangle 0.001, r^{2}=0.94\right)$.

A possible association between osteoporosis and the lipid profile could be explained at a molecular level as well: Franceschi described the "global reduction in the capacity to cope with a variety of stressors and a concomitant progressive increase in proinflammatory status" (the "inflammaging" theory) which can lead to age related disea ses such as osteoporosis (32). Another theory, based on the epidemiological link between hyperlipidemia, visceral obesity and osteoporosis, supports these findings through the "osteo-lipo-vascular interactions" which exist due to the common origin of osteo- blasts, vascular smooth muscle cells and adipocytes (33).

Limitations to this study include its retrospective design. In addition, a signific ant correlation for the entire patient cohort, as well as by subgroups according to previous fracture, was not demonstrable. While the lack of very strong correlations, albeit many with statistical significance, might be viewed as a limitation, one would not expect to find very high rvalues when only one piece of a pathogenic puzzle is identified in the context of a multifactorial disea se like osteoporosis. As such, this new data sheds light on the plausible link between osteoporosis and the lipid profile, link, which if proven through prospective randomized studies would allow for a better treatment of patients with osteoporosis.

One of the main strengths of our study is that, in comparison to previous reports, we have stratified the subjects according to age. This is also one of the first c linic al studies associating postmenopa usal osteoporosis with the circulating lipid profile both with and without statin use and/or antiresorptive drug use, while taking into consideration age groups. As such, the analyses provide support for the idea that BMD may be associated with the entire lipid profile for postmenopausal women older than 50 years. Future studies may elucidate molecular or biochemical mechanisms for these observations.

\section{References:}

1 Mundy G, Garrett R, Harris S, Chan J, Chen D, Rossini G, Boyce B, Zhao M, Gutierrez G. Stimulation of bone formation in vitro and in rodents by statins. Science. 1999;286:1946-1949.

2 Fisher JE, Rogers MJ, Halasy JM, Luckman SP, Hughes DE, Masarachia PJ, Wesolowski G, Russell RG, Rodan GA, Reszka AA Alendronate mechanism of action: geranylgeraniol, an intermediate in the mevalonate pathway, prevents inhibition of osteoclast formation, bone resorption, and kinase activation in vitro Proc Natl Acad Sci U S A. 1999;96:133-138.

3 Chen JS, Sambrook PN. Antiresorptive therapies for osteoporosis: a clinical overview. Nat Rev Endocrinol. 2011;8:81-91.

4 Cruz AC, Gruber BL. Statins and osteoporosis: can these lipidlowering drugs also bolster bones? Cleve Clin J Med. 2002; 69:277-278, 280-282, 287-288.

5 Huang $\mathrm{W}$, Shang WL, Li DH, Wu WW, Hou SX. Simvastatin protects osteoblast against $\mathrm{H}_{2} \mathrm{O}_{2}$-induced oxidative damage via inhibiting the upregulation of Nox4. Mol Cell Biochem. 2012;360: 71-77.

6 Tanriverdi HA, Barut A, Sarikaya S. Statins have additive effects to vertebral bone mineral density in combination with risedronate in hypercholesterolemic postmenopausal women. Eur J Epidemiol. 2004;19:1105-1112 
7 Lupattelli G, Scarponi AM, Vaudo G, Siepi D, Roscini AR, Gemelli F, Pirro M, Latini RA, Sinzinger H, Marchesi S, Mannarino E. Simvastatin increases bone mineral density in hypercholesterolemic postmenopausal women. Metabolism. 2004; 53:744-748.

8 Bauer DC, Mundy GR, Jamal SA, Black DM, Cauley JA, Ensrud $\mathrm{KE}$, van der Klift M, Pols HA. Use of statins and fracture: results of 4 prospective studies and cumulative meta-analysis of observational studies and controlled trials. Arch Intern Med. 2004 164:146-152.

9 Bakhireva LN, Shainline MR, Carter S, Robinson S, Beaton SJ, Nawarskas JJ, Gunter MJ. Synergistic effect of statins and postmenopausal hormone therapy in the prevention of skeletal fractures in elderly women. Pharmacotherapy. 2010;30:879-887.

10 Montagnani A, Gonnelli S, Cepollaro C, Pacini S, Campagna MS, Franci MB, Lucani B, Gennari C. Effect of simvastatin treatment on bone mineral density and bone turnover in hypercholesterolemic postmenopausal women: a 1-year longitudinal study. Bone. 2003;32:427-433.

11 Chan KA, Andrade SE, Boles M, Buist DS, Chase GA, Donahue JG, Goodman MJ, Gurwitz JH, LaCroix AZ, Platt R. Inhibitors of hydroxymethylglutaryl-coenzyme A reductase and risk of fracture among older women. Lancet. 2000;355:2185-2188.

12 LaCroix AZ, Cauley JA, Pettinger M, Hsia J, Bauer DC, McGowan J, Chen Z, Lewis CE, McNeeley SG, Passaro MD, Jackson RD. Statin use, clinical fracture, and bone density in postmenopausal women: results from the Women's Health Initiative Observational Study. Ann Intern Med. 2003;139:97-104.

13 Chan MH, Mak TW, Chiu RW, Chow CC, Chan IH, Lam CW. Simvastatin increases serum osteocalcin concentration in patients treated for hypercholesterolaemia. J Clin Endocrinol Metab. 2001; 86:4556-4559.

14 Lencel P, Magne D. Inflammaging: the driving force in osteoporosis? Med Hypotheses. 2011;76:317-321

15 Siasos G, Tousoulis D, Oikonomou E, Zaromitidou M, Stefanadis C, Papavassiliou AG. Inflammatory markers in hyperlipidemia: from experimental models to clinical practice. Curr Pharm Des. 2011;17:4132-4146.

16 Kvasnicka T, Kvasnicka J, Ceska R, Vrablik M. Increase of inflammatory state in overweight adults with combined hyperlipidemia. Nutr Metab Cardiovasc Dis. 2003;13:227-231.

17 Sage AP, Lu J, Atti E, Tetradis S, Ascenzi MG, Adams DJ, Demer LL, Tintut Y. Hyperlipidemia induces resistance to PTH bone anabolism in mice via oxidized lipids. J Bone Miner Res. 2011; 26:1197-1206

18 Tarakida A, Iino K, Abe K, Taniguchi R, Higuchi T, Mizunuma H, Nakaji S. Hypercholesterolemia accelerates bone loss in postmen- pausal women. Climacteric. 2011;14:105-111.

19 Yamaguchi T. Bone metabolism in dyslipidemia and metabolic syndrome. Clin Calcium. 2011;21:677-682.

20 Tintut Y, Morony S, Demer LL. Hyperlipidemia promotes osteoclastic potential of bone marrow cells ex vivo. Arterioscler Thromb Vasc Biol. 2004;24:e6-e10.

21 Majima T, Shimatsu A, Komatsu Y, Satoh N, Fukao A, Ninomiya K, Matsumura T, Nakao K. Increased bone turnover in patients with hypercholesterolemia. Endocr J. 2008;55:143-151.

22 Orozco P. Atherogenic lipid profile and elevated lipoprotein (a) are associated with lower bone mineral density in early postmenopausal overweight women. Eur J Epidemiol. 2004;19:11051112.

23 National Institutes of Health Osteoporosis and Related Bone Diseases National Resource Center. Bone Mass Measurement: What the numbers mean [internet] May 2009 [cited June 2013].

24 Makovey J, Chen JS, Hayward C, Williams FM, Sambrook PN. Association between serum cholesterol and bone mineral density. Bone. 2009;44:208-213.

25 Tankó LB, Bagger YZ, Nielsen SB, Christiansen C. Does serum cholesterol contribute to vertebral bone loss in postmenopausal women? Bone. 2003;32:8-14.

26 Uyama O, Yoshimoto Y, Yamamoto Y, Kawai A. Bone changes and carotid atherosclerosis in postmenopausal women. Stroke. 1997;28:1730-1732.

27 Samelson EJ, Cupples LA, Hannan MT, Wilson PW, Williams SA, Vaccarino V, Zhang Y, Kiel DP. Long-term effects of serum cholesterol on bone mineral density in women and men: the Framingham Osteoporosis Study. Bone. 2005;34:557-561.

28 Solomon DH, Avorn J, Canning CF, Wang PS. Lipid levels and bone mineral density. Am J Med. 2005;118:1414.

29 Wu LY, Yang TC, Kuo SW, Hsiao CF, Hung YJ, Hsieh CH, Tseng HC, Hsieh AT, Chen TW, Chang JB, Pei D. Correlation between bone mineral density and plasma lipids in Taiwan. Endocr Res. 2003;29:317-325.

30 Ackert-Bicknell CL. HDL cholesterol and bone mineral density: is there a genetic link? Bone. 2012;50:525-533.

31 Karasik D, Kiel DP. Evidence for pleiotropic factors in genetics of the musculoskeletal system. Bone. 2010;46:1226-1237.

32 Franceschi C, Bonafè M, Valensin S, Olivieri F, De Luca M, Ottaviani E, De Benedictis G. Inflamm-aging. An evolutionary perspective on immunosenescence. Ann N Y Acad Sci. 2000;908 244-254.

33 Koshiyama H, Ogawa Y, Tanaka K, Tanaka I. The unified hypothesis of interactions among the bone, adipose and vascular systems: 'osteo-lipo-vascular interactions'. Med Hypotheses. 2006; 66:960-963. 